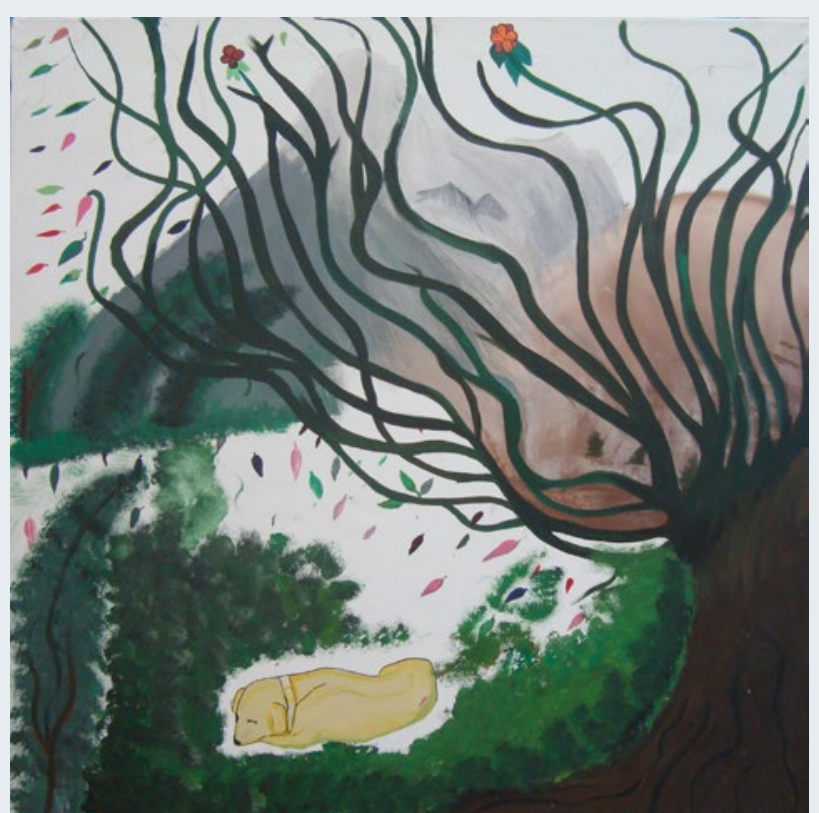

Abb. 4: Das unfertige Bild der 14-jährigen Jesidin Siham, die mit ihrer Familie aus dem Nordirak geflohen ist.

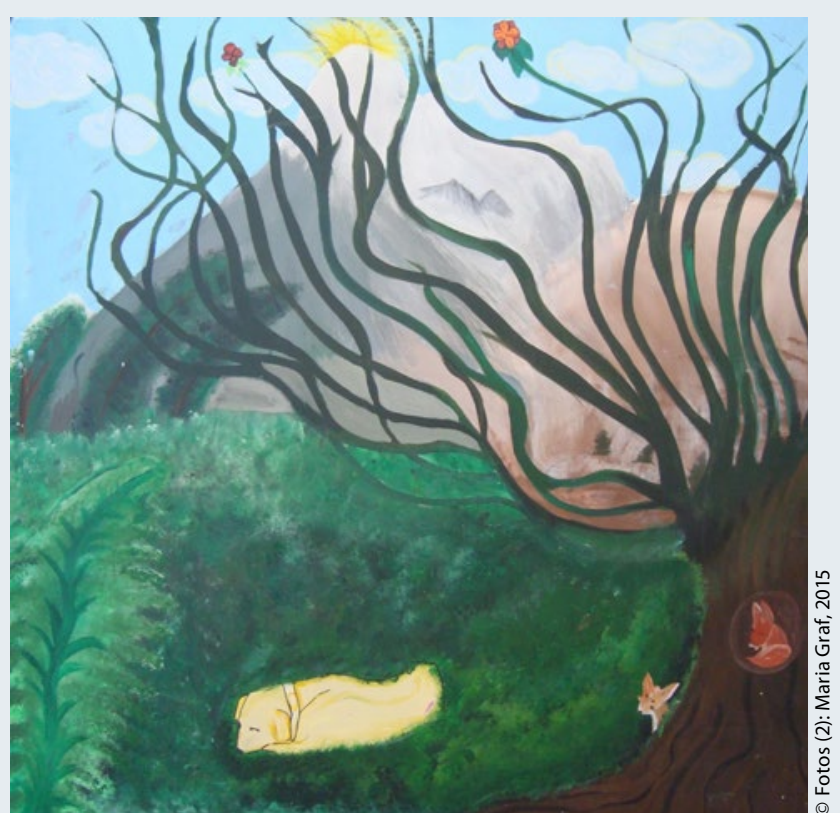

Abb. 5: Bearbeitung des Bildes nach längerer Pause. Die dargestellte Atmosphäre hat sich deutlich geändert.

\title{
Beispiel aus der Arbeit in der Kunsttherapiegruppe von Refugio München
}

Siham (Name geändert) nimmt wöchentlich an einer Kunsttherapiegruppe von Refugio München teil. In der Ecke des Raumes steht eine Staffelei mit ihrem Gemälde. Die großformatige Leinwand hat sie selbst gebaut und grundiert. Seit mehreren Wochen arbeitet sie nun an diesem Landschaftsbild mit den vielen übereinander liegenden Farbschichten (Abb. 4). Das Bild ist noch immer im Entstehungsprozess. Betrachtet man den vorläufigen Zwischenstand, so fällt der Blick zunächst auf den gelben, schlafenden Hund, eine bekannte kunstgeschichtliche Figur, die sich Siham aus dem Gemälde von Franz Marc "Liegender Hund im Schnee" aus dem Jahr 1910/11 entliehen hat. Sein gelbes Fell leuchtet im Kontrast zu den dunklen Farben seiner Umgebung. Auf der rechten Seite im Vordergrund wächst ein starker Baum aus dem Boden, der im Stil von Mangazeichnungen dargestellt ist. Er blüht und verliert doch gleichzeitig seine bunten Blätter. Dahinter erstreckt sich ein nebliges und düsteres Gebirge mit langen, dunklen Bäumen, die sich im Wind biegen. Im Gegensatz zu Franz Marc, der in seinem Bild einen harmonischen Zusammenhang zwischen Tier und Natur herstellt, wirkt die Figur hier einer fremden Umgebung ausgesetzt. Sie hat noch keinen festen Boden unter sich. Doch das Bild stellt auch einen Ort des Wandels dar: Das Wetter kann sich möglicherweise schnell ändern, der Baum hat genügend Kraft weiter zu wachsen, der Hund wird sich wieder auf den Weg machen. So lautet zumindest die Einschätzung der Kunsttherapiegruppe, die sich in einer gemeinsamen Bildbesprechung eine Geschichte zu dem Gemälde ausgedacht hat.

Viele der angesprochenen Punkte weisen eine Parallele zur Malerin des Bildes auf. Das Mädchen Siham ist 14 Jahre alt und kommt aus dem Nordirak. Als Jesidin ist sie Teil einer verfolgten religiösen Minderheit, weshalb sie gemeinsam mit ihrer Familie nach Deutschland geflohen ist.

Über einen längeren Zeitraum hat Siham an ihrem Landschaftsbild nicht weitergearbeitet. Konflikte mit den Eltern aufgrund der strengen Reglementierung sowie Probleme in der Schule haben dazu geführt, dass sie in der Kunsttherapiestunde lieber reden und streiten wollte, als an einem unfertigen Bild weiter zu malen.

Doch nach einer Weile und mit etwas gutem Zuspruch gibt sie dem Bild erneut eine Chance. Sie richtet sich in der gewohnten Ecke des Raumes ein, stellt die Leinwand auf die Staffelei, mischt sich ihre Farbpalette und setzt den Kopfhörer mit ihrem Lieblingssoundtrack aus Bollywood auf. Es ist ein warmer Frühlingstag und Siham malt neben dem offenen Fenster. Sie ist ganz in die Landschaft versunken. Mittendrin zieht sie ihre Schuhe aus und wirft sie hinter sich. Die Gruppe amüsiert sich über sie, aber das bekommt sie gar nicht mit.

Als die Doppelstunde zu Ende ist, strahlt Siham über das ganze Gesicht. Auch in ihrem Bild hat sich in dieser kurzen Zeit einiges verändert (Abb. 5): Die Atmosphäre hat sich durch den blauen Himmel und den Sonnenschein aufgehellt. Siham hat die Wiese vervollständigt, wodurch der schlafende Hund jetzt einen Boden unter den Füßen hat. Am Baum tauchen zwei kleine Tiere auf, ein Fuchs und ein Eichhörnchen. Beide beobachten die Szenerie wie Wächter des Schlafes. Das Landschaftsbild drückt auf einmal ein Gefühl von Geborgenheit aus. Siham erklärt uns, dass das Bild noch lange nicht fertig sei. Es fehle noch so viel. Wie die Geschichte weitergeht, bleibt ihr Geheimnis. In der Kunst ist alles möglich.

Maria Graf 